\title{
DIAGNÓSTICO DA PERCEPÇÃO DOS MORADORES SOBRE A ARBORIZAÇÃO URBANA NA VILA ESTAÇÃO COLÔNIA - BAIRRO CAMOBI, SANTA MARIA - RS.
}

\author{
Cristiane Roppa ${ }^{1}$, Jaiane Rodrigues Falkenberg ${ }^{2}$, Diego Martins Stangerlin ${ }^{3}$, Flávia Gizele \\ König Brun ${ }^{4}$, Eleandro José Brun ${ }^{5}$, Solon Jonas Longhi ${ }^{6}$
}

\begin{abstract}
RESUMO
O desenvolvimento de nossa capacidade de percepção constitui-se hoje motivo para avaliação de muitos estudos, até mesmo em arborização urbana. Esse estudo teve como objetivo avaliar o grau de conscientização dos moradores da Vila Estação Colônia - Bairro Camobi, Santa Maria - RS, a respeito da arborização urbana, visando obter informações sobre as necessidades, críticas e sugestões para colaboração na elaboração de futuros planos de gestão. Aplicando-se aos moradores, um questionário com dez questões abertas e fechadas, os quais foram escolhidos por amostragem aleatória, com o intuito de detectar os seus anseios e opiniões sobre a arborização da Vila Estação Colônia. Após realizou-se a análise dos dados através de planilhas eletrônicas. Os resultados obtidos indicaram 0 reconhecimento da arborização urbana $(83,1 \%$ e $49,2 \%$ dos entrevistados citaram como vantagem o fornecimento de sombra e redução do calor) e, por esse motivo, para um eficiente planejamento e manutenção da arborização urbana pelas administrações públicas faz-se necessário considerar a percepção da população sobre a arborização urbana.
\end{abstract}

Palavras-chave: Percepção ambiental, arborização urbana, Vila Estação Colônia

\footnotetext{
1.Engenheira Florestal, mestranda, PPGCAF-IF/UFRRJ. Seropédica - RJ, cris_roppa@ufrrj.br. 2.Engenheira Florestal, Cruz Alta - RS. E-mail: jaianefalkenberg@yahoo.com.br.

3.Engenheiro Florestal, mestrando, PPGEF-UFSM.Santa Maria-RS, diego_stangerlin@yahoo.com.br. 4.Engenheira Florestal, MSc. Aluna de especialização em Educação Ambiental - CCR - UFSM. Santa Maria RS, flaviakonig@mail.ufsm.br.

5.Engenheiro Florestal, doutorando do PPGEF-UFSM. Santa Maria - RS, eleandrojbrun@yahoo.com.br.

6.Engenheiro Florestal, Professor, CCR - UFSM. Santa Maria - RS, solon.longhi@pesquisador.cnpq.
} 


\title{
DIAGNOSTIC OF THE POPULATION'S PERCEPTION ON THE URBAN TREES IN VILLA ESTAÇÃO COLÔNIA - CAMOBI NEIGHBORHOOD, SANTA MARIA - RS.
}

\begin{abstract}
Nowadays the development of our perception capacity has been the reason for evaluation of many studies even when it's related to the perception of the importance of the urban trees. The objective of this paper was to evaluate the population's degree from the Vila Estação Colônia - Neighborhood Camobi - Santa Maria - RS regarding the urban trees in which was trying to get information about theirs needs as well as their opinions and suggestions to collaborate for the elaboration of the future administration plans. A survery was applied and it contain ten opened and closed questions. The population to apply the survery were selected by aleatory sampling and it had the objective to get to know the population's from Vila Estação Colônia opinion as well as their yearning. After that an electronic planilhas was used to do the analysis of the data. The results obtained indicated the recognition of the urban trees (the interviewers $83,1 \%$ and $49,2 \%$ mentioned as advantage the supping shade and reduction of the heat) for that reason to get an efficient planning and maintenance of the urban trees by the public administrations is necessary to consider the population perception about the urban trees.
\end{abstract}

Key-words: environmental perception, urban trees, small town Estação Colônia 


\section{INTRODUÇÃO}

Desde muito tempo, o homem vem trocando o meio rural pelo meio urbano. As cidades foram crescendo, na maioria das vezes de forma muito rápida e desordenada, sem um planejamento adequado de ocupação, provocando vários problemas que interferem sobremaneira na qualidade de vida do homem que vive na cidade (Pivetta \& Silva Filho, 2002).

De acordo com Moro apud Zinkoski \& Loboda (2005) a constante urbanização nos permite assistir, em nossos grandes centros urbanos, a problemas cruciais do desenvolvimento nada harmonioso entre a cidade e a natureza. Assim, o autor citado acima descreve que podemos observar a substituição de valores naturais por ruídos, concreto, máquinas, edificações, poluição, etc., o que ocasiona entre a obra do homem e a natureza crises ambientais cujos reflexos negativos contribuem para degeneração do meio ambiente urbano, proporcionando condições nada ideais para a sobrevivência humana.

Para um melhor planejamento e compreensão do ambiente urbano, fazem-se necessários estudos que enfoquem a percepção da população em relação ao meio ambiente, pois no uso cotidiano dos espaços, dos equipamentos e serviços urbanos, a população sente diretamente o impacto da qualidade ambiental (Rio \& Oliveira, 1999).

Assim sendo, percepção, por definição, é o ato, efeito ou faculdade de perceber, adquirir conhecimento a partir de algo por meio dos sentidos, compreender, ouvir. Dessa maneira, a percepção tem o sentido de aquisição de informações pelos atores sociais, oriundos da realidade do meio externo e de sua própria interação com o mundo material que os cerca. Assim, observa-se a percepção como um processo cognitivo/cultural que envolve mecanismos de percepção externa (os cinco sentidos) e a elaboração mental (Amante, 2001).

Entre as formas de se estudar a percepção ambiental encontramos as mais diversas: questionários, mapas mentais ou contorno, representação fotográfica, etc. Existem ainda trabalhos em percepção ambiental que buscam também promover a sensibilização, bem como o desenvolvimento do sistema de percepção e compreensão do ambiente (Faggionato, 2005).

A percepção ambiental abrange a compreensão das inter-relações entre o meio ambiente e os atores sociais, ou seja, como a sociedade percebe o seu meio circundante, expressando suas opiniões, expectativas e propondo linhas de conduta; desta forma os estudos que se caracterizam pela aplicação da percepção ambiental objetivam investigar a maneira como o homem enxerga, interpreta, convive e se adapta à realidade do meio em que vive, principalmente em se tratando de ambientes instáveis ou vulneráveis socialmente e naturalmente (Okamoto, 1996). 
O estudo da percepção ambiental é de fundamental importância, por meio dele é possível conhecer a cada um dos indivíduos envolvidos, facilitando a realização de um trabalho com bases locais, partindo da realidade do público alvo sabemos como os indivíduos percebem o ambiente em que vivem, suas fontes de satisfação e insatisfação (Faggionato, 2005).

Dentro da proposição ressaltada pela UNESCO em 1973 "uma das dificuldades para a proteção dos ambientes naturais está na existência de diferenças nas percepções dos valores e da importância dos mesmos entre os indivíduos de culturas diferentes ou de grupos sócio-econômicos que desempenham funções distintas, no plano social, nesses ambientes". Neste contexto o termo "Percepção Ambiental" passa a ser usado no sentido amplo de "uma tomada de consciência do ambiente pelo homem" (Maroti, 2005). O homem está constantemente agindo sobre o meio a fim de sanar suas necessidades e desejos.

Cada indivíduo percebe, reage e responde diferentemente frente às ações sobre o meio, logo as respostas ou manifestações resultam das percepções, dos processos cognitivos, julgamentos e expectativas de cada indivíduo. Embora nem todas as manifestações psicológicas sejam evidentes, são constantes, e afetam nossa conduta, na maioria das vezes, inconscientemente (Faggionato, 2005).

Segundo Oliveira apud Malavasi \& Malavasi (2001) os parâmetros utilizados para a avaliação da arborização urbana baseiam-se geralmente na observação e mensuração de variáveis biológicas embora tenha sido já admitido que fatores sentimentais, psicológicos e estéticos são importantes. A arborização de cidades surgiu com o intuito de garantir o veículo atávico do homem com o "natural", a fim de desfrutar seus principais benefícios como: redução de ruídos, melhoria do microclima, alteração do campo visual, recreação e lazer urbano, portanto as propriedades inerentes ao bem-estar do homem citadino estão diretamente vinculadas ao componente vegetal que faz parte dos aglomerados urbanos, ou seja, arborizar áreas significa atender a dupla natureza humana: a biológica e cultural (Malavasi \& Malavasi, 2001).

A arborização em calçadas, embora desempenhe uma função essencial e insubstituível para a sustentabilidade do ambiente urbano, quando não planejada pode representar prejuízos aos agentes sociais. A presença de árvores é essencial para amenizar os microclimas mais quentes, aumentando a umidade do ar, reduzir a reflexão da luz solar junto à calçada, reduzir a poluição do ar, sonora e visual, interceptar a água da chuva e ainda serve de refúgio para a fauna remanescente na cidade, com especial destaque para os pássaros, que podem ser importantes predadores, exercendo o controle do tamanho populacional de pragas e de vetores de doenças. A arborização de vias quando mal planejada, pode acarretar: a) dificuldade de circulação de pessoas; b) entupimento de encanamentos pluviais em virtude da biomassa vegetal não recolhida eficientemente pelo 
serviço de limpeza pública, podendo contribuir à ocorrência de enchentes; c) os canteiros mal dimensionados podem vir futuramente a comprometer seu entorno (uma vez que nessas circunstâncias, o desenvolvimento das plantas lenhosas pode promover quebra de calçadas e até mesmo o desmonte de muros); e d) a carência de poda, que se reflete em risco, tanto à rede elétrica aérea quanto às próprias residências.

A realização desta pesquisa na Vila Estação Colônia justifica-se principalmente devido aos problemas relacionados à arborização urbana, a forma inadequada como foi implantada, a má distribuição e atual situação da arborização das vias públicas, que desencadeia nos moradores desta vila, muitas vezes um desinteresse em relação à arborização urbana.

Diante dos problemas apresentados, o estudo teve como objetivo avaliar o grau de conscientização dos moradores da Vila Estação Colônia - Bairro Camobi, Santa Maria -RS a respeito da arborização urbana, visando despertar o interesse e a participação dos moradores no que se refere à arborização urbana e obter informações sobre as necessidades, críticas e sugestões dos moradores da Vila em estudo para colaboração na elaboração de futuros planos de gestão.

\section{MATERIAIS E MÉTODOS}

\section{Descrição do Local}

O presente estudo foi realizado na Vila Estação Colônia, localizado no Bairro Camobi, município de Santa Maria-RS. Localizada nas coordenadas geográficas $29^{\circ} 42^{\prime} 19^{\prime \prime}$ de latitude e $53^{\circ} 43^{\prime} 44^{\prime \prime}$ de longitude. Apresenta uma população com 1.420 habitantes e área total de $19.760 \mathrm{~m}^{2}$. Constitui-se de nove ruas, sendo elas: Osmar Rossi, Rua 3, Rua 7, Vila Lobos, Rua 8, Álvaro Hoppe, Murilo V. Bichuetti, Congonhas, Rua 5. Na Figura 1, podese visualizar a área onde foi realizado o presente estudo. 


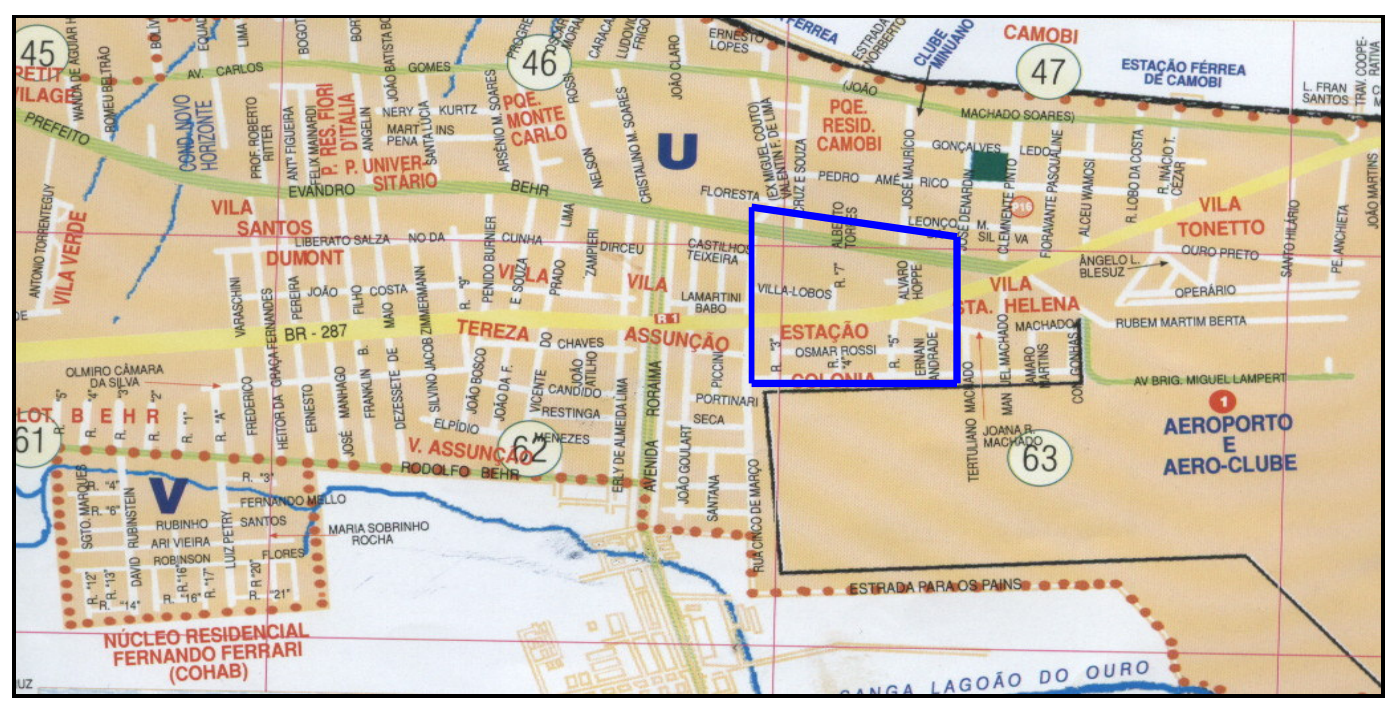

Figura 1: Área de Estudo (destacada em azul). Fonte: Prefeitura Municipal de Santa Maria (2002).

O clima da região é do tipo subtropical temperado, do tipo "Cfa 2", segundo a classificação de Köppen (Moreno, 1961), caracterizada por temperatura média anual entre 17,9 e $19,2^{\circ} \mathrm{C}$. As chuvas são bem distribuídas ao longo do ano sendo que a precipitação média anual fica em torno de 1400 a $1760 \mathrm{~mm}$.

O relevo apresenta-se suavemente ondulado, caracterizado pela presença de coxilhas e planícies aluviais, com cotas altimétricas variando de 40 a 200 metros, caracterizando uma paisagem sem grande variação altimétrica (Spiazzi, 2002). O solo classifica-se como pertencente às Unidades de Mapeamento São Pedro e Santa Maria, sendo que os mesmos denominam-se, respectivamente, como: Argissolo Vermelho-Amarelo de textura média com relevo ondulado e substrato arenítico e Brunizém Hidromórfico de textura média, de relevo levemente ondulado e substrato siltito-arenítico (Streck, et al., 2002).

\section{Metodologia específica}

A metodologia empregada para realização do presente estudo se baseou em um questionário (anexo 1) previamente elaborado contendo questões objetivas e questões do tipo aberta (baseada em respostas de opinião própria), as quais foram dialogadas com moradores, com o intuito de detectar os anseios e opiniões dos moradores sobre a arborização da Vila Estação Colônia. A aplicação dos questionários foi estipulada por amostragem aleatória, inicialmente escolhia-se uma das nove ruas, sendo após cada três residências aplicado um questionário, o qual relacionava os seguintes assuntos: número de 
moradores por residência, grau de escolaridade, grau de arborização da rua, vantagens e desvantagens apresentadas pela arborização, encaminhamento de necessidades a órgãos públicos e privados (Prefeitura municipal, companhias elétricas e telefônicas, etc.) referentes à implantação e manutenção da arborização, forma de colaboração por parte dos moradores a manutenção e melhoria da arborização, indicação de espécies que estes desejariam que fossem implantadas e se estariam dispostos a colaborar financeiramente com a arborização da rua e quanto dariam, caso esta fosse implantada.

Depois de efetuadas as entrevistas, procederam-se a compilação e análise dos dados obtidos, através de planilhas informatizadas.

\section{RESULTADOS E DISCUSSÃO}

Ao todo foram feitas 65 entrevistas, sendo que o número total de moradores nas residências entrevistadas foi de 224. Em relação ao grau de escolaridade, $35,4 \%$ dos entrevistados possuem ensino médio completo, 27,7\% possuem ensino fundamental incompleto, $23,1 \%$ ensino superior completo, $7,7 \%$ ensino médio incompleto, $3,1 \%$ ensino fundamental completo, $1,5 \%$ ensino superior incompleto e $1,5 \%$ dos entrevistados são analfabetos.

A vila foi classificada como razoavelmente arborizada por $49,2 \%$, pouco arborizada por $38,5 \%$ e muito arborizada por $12,3 \%$ dos entrevistados, no entanto, este tipo de avaliação tende a ser muito subjetiva, dependendo em grande parte da maior ou menor vivência do morador no local, pelo fato que muitos tendem a avaliar a arborização da vila apenas levando em conta a arborização de sua rua ou mesmo a que se encontra enfrente a sua casa.

Algumas vantagens foram observadas na arborização da vila, pelos moradores, estas estão apresentadas na Figura 2. 


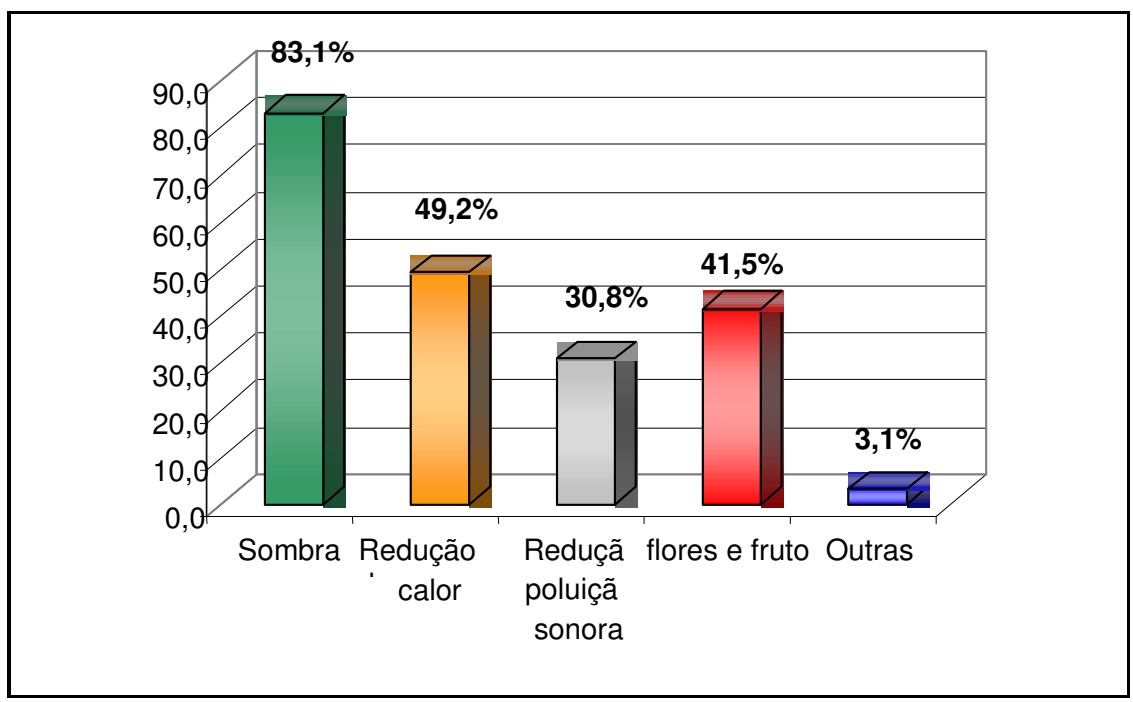

Figura 2: Vantagens apresentadas na arborização urbana observada pela população da Vila Estação Colônia, Bairro Camobi, Santa Maria, RS.

Entre as vantagens apontadas pela população nota-se que a maioria observa, os benefícios na melhoria da qualidade do microclima urbano proporcionado pela arborização urbana, como demonstrado na figura acima, onde 83,1\% apontaram como vantagem à produção de sombra, 49,2\% evidenciaram a redução do calor, sendo que estas vantagens vão aparecer diretamente relacionadas na questão quanto à indicação de espécies por parte dos moradores. Estas vantagens se justificam pela ocorrência de altas temperaturas durante o verão, as quais impulsiona a população a buscar diferentes meios que the proporcionem maior conforto térmico. Segundo Santos \& Teixeira (2001) embora a vegetação, não possa controlar totalmente as condições de desconforto, ela pode, eficientemente, abrandar a sua intensidade. Os mesmos autores salientam que a vegetação proporciona índices mais altos de umidade relativa do ar e os maiores valores são atingidos no verão quando a planta encontra-se com a folhagem, responsável pelo efeito de evapotranspiração.

Outra característica bastante enfatizada pela população seria da presença de flores e frutos $(41,5 \%)$, que demonstra que um dos aspectos observados pelos moradores na implantação de espécies é a melhoria estética e funcionalidade do ambiente, que por sua vez indiretamente agrega valor econômico ao seu imóvel, mas principalmente lhes traz bemestar e melhoria na qualidade de vida.

Porém quanto à presença de frutos nas árvores, observa-se um ganho ambiental e econômico, pois serve de atrativo e muitas vezes de refúgio, para a avifauna urbana e de alimentação para os moradores, mas em muitos casos, dependendo da espécie, causa transtornos e desvantagens como a sujeira das calçadas, que segundo os moradores da Vila Estação Colônia, é umas das principais desvantagens apresentadas pela arborização 
urbana, embora eles tenham considerado mais como sujeira as folhas mortas que se acumulam na calçada (Figura 3). Uma boa alternativa para substituir o uso de espécies frutíferas, que na sua maioria não são adequadas para a arborização de ruas, é a introdução de espécies de frutíferas nativas, que apresentem potencial para tal finalidade. Santos \& Teixeira (2001) afirmam que algumas espécies vegetais, com ênfase nas frutíferas nativas, são responsáveis pelo abrigo e alimentação da avifauna, assegurando-lhes condições de sobrevivência.

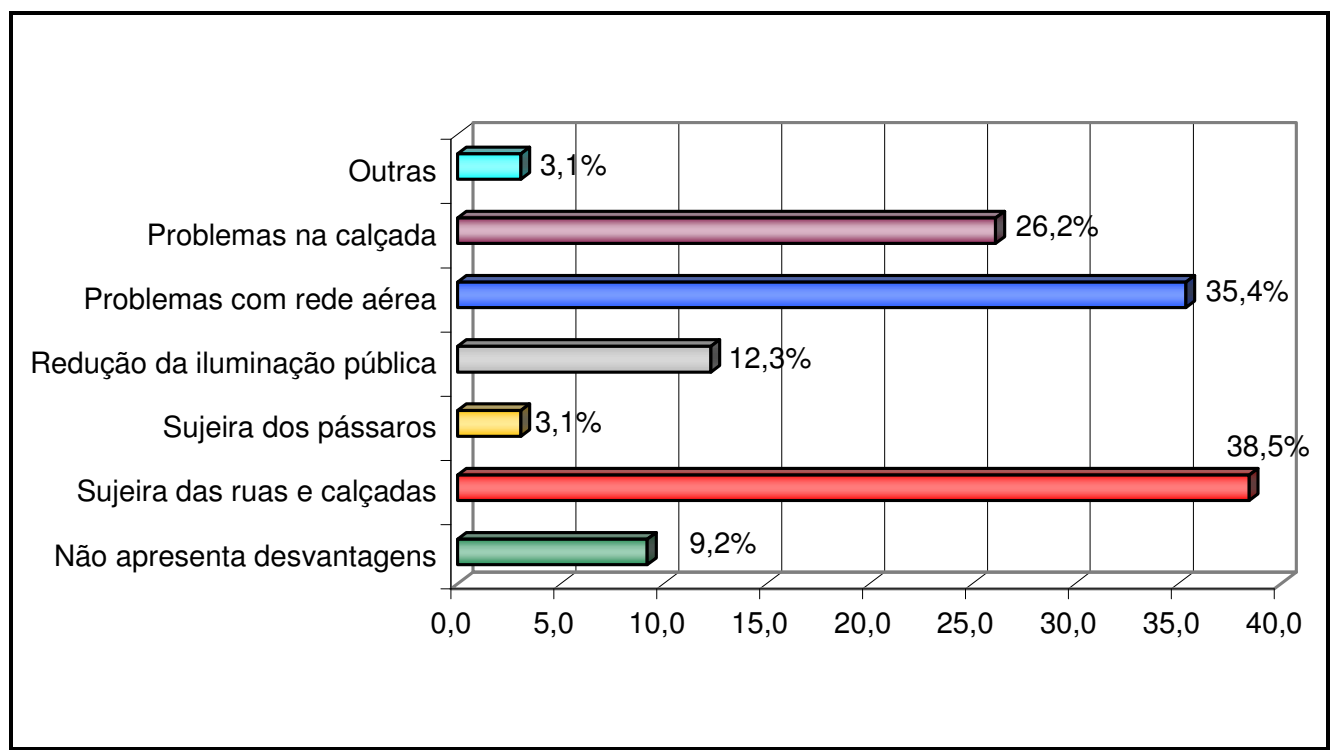

Figura 3: Desvantagens observadas pela população da Vila Estação Colônia, Bairro Camobi, Santa Maria, RS.

Com base na Figura 3, observa-se que $9,2 \%$ da população não observam desvantagens na arborização, o que pode demonstrar ser um bom nível de conscientização da população em relação da importância da presença da arborização no meio urbano e seus benefícios gerados ou então que estas pessoas nunca se depararam com problemas da arborização urbana ou até mesmo reagem negligenciando-os. Entre as desvantagens apontadas destacaram-se: sujeira das ruas e calçadas (38,5\%), problemas com a rede aérea $(35,4 \%)$ e problemas nas Calçadas $(26,2 \%)$, sendo que todas estas desvantagens, somente são originadas devido à falta de informação desta população no que se refere à arborização urbana e a falta de orientação técnica para recomendação de espécies adequadas as condições encontradas no ambiente da Vila, visto que a grande parte das espécies presentes na arborização foram introduzidas pelos próprios moradores. Para Santos \& Teixeira (2001), a árvore como elemento estruturador de espaços, responsável por 
qualidades estético-visuais e de bem-estar, passa a construir um problema urbano, decorrente de planos ineficientes, inexistência de políticas no setor, improvisos e falta de conscientização.

Quanto à opinião de para quem dirigir reclamações sobre a arborização urbana (Figura 4), 52,3\% dos entrevistados, disseram que reclamações desse tipo seriam encaminhadas para Prefeitura Municipal através da Secretaria de Proteção Ambiental, $10,8 \%$ encaminhariam as companhias responsáveis pela energia elétrica e telefonia, $3,1 \%$ a outros órgãos ou a sua Associação de Moradores e 36,9\% não opinaram, pois não sabiam a quem encaminhar as suas reclamações, dúvidas ou sugestões, o que reflete em uma situação de falta de orientação técnica aos moradores, ocasionando diretamente a implantação de espécies inadequadas, e principalmente danos mecânicos a árvores pela realização de podas sem orientação, desconfigurando a copa e reduzindo o efeito paisagístico da árvore, além de na implantação de um plano de arborização, às áreas não arborizadas da Vila por parte destes órgãos, há uma grande possibilidade de insucesso por falta de adesão da população, devido ao desconhecimento destes órgãos dos reais anseios e necessidades da população do local.

Malavasi \& Malavasi (2001) em um estudo onde avaliaram a arborização urbana pelos residentes em Mal. Cândido Rondon, Paraná obtiveram dados de que $73 \%$ da população encaminharia reclamações referentes à arborização urbana à Prefeitura Municipal, enquanto que $14 \%$ encaminhariam a companhia de eletricidade COPEL, afirmavam que as respostas estavam em conformidade com a constatação de que a arborização urbana consiste de um bem público e, portanto recai sobre os ditames da administração municipal. Segundo Silva citado por Malavasi \& Malavasi (2001) as prefeituras municipais devem executar e manter a arborização urbana, pois a competência para tal reside nos planos diretores e leis do uso do solo dos municípios ou regiões metropolitanas os quais devem observar os princípios e limites previstos no art. $2^{\circ}$, parágrafo único do Código Florestal que foi acrescentado pela lei 7.803/89. 


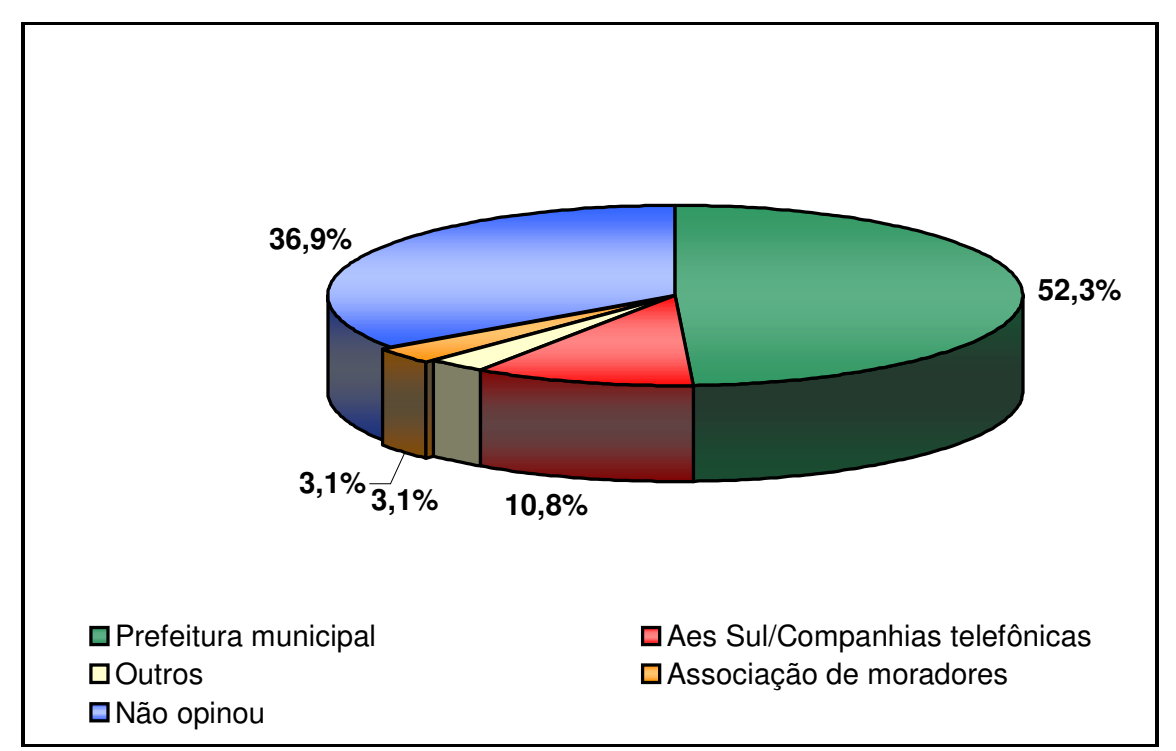

Figura 4: Principais órgãos públicos e privados utilizados pelos moradores da Vila Estação Colônia para o encaminhamento de questões relacionadas à arborização urbana.

Quanto à colaboração da população com a arborização da vila, $81,5 \%$ dos moradores afirmaram que colaboram de alguma forma com a arborização, e 18,5\% não colaboram com a mesma.

Dentre as formas de colaboração para a manutenção da arborização por parte dos moradores (Figura 5), 64,6\% alegaram que colaboram não danificando as árvores, seguido de 44,6\% plantando árvores e 41,5\% realizando manutenção e podando; porém, estas duas últimas formas repercute na maioria das vezes em equívocos anteriormente mencionados como: implantação de espécie inadequadas, que danificam calçadas e a rede aérea ou também a realização de poda de forma desnecessária, podando indivíduos muito jovens, ou de forma desordenada, muitas vezes podendo até ocasionar a mutilação da árvore segundo Castro (2004), além de danificar a copa, deixando a árvore exposta ao ataque de pragas e doenças pelo estresse fisiológico imposto pela prática, o que freqüentemente ocorre em cidades do interior. 


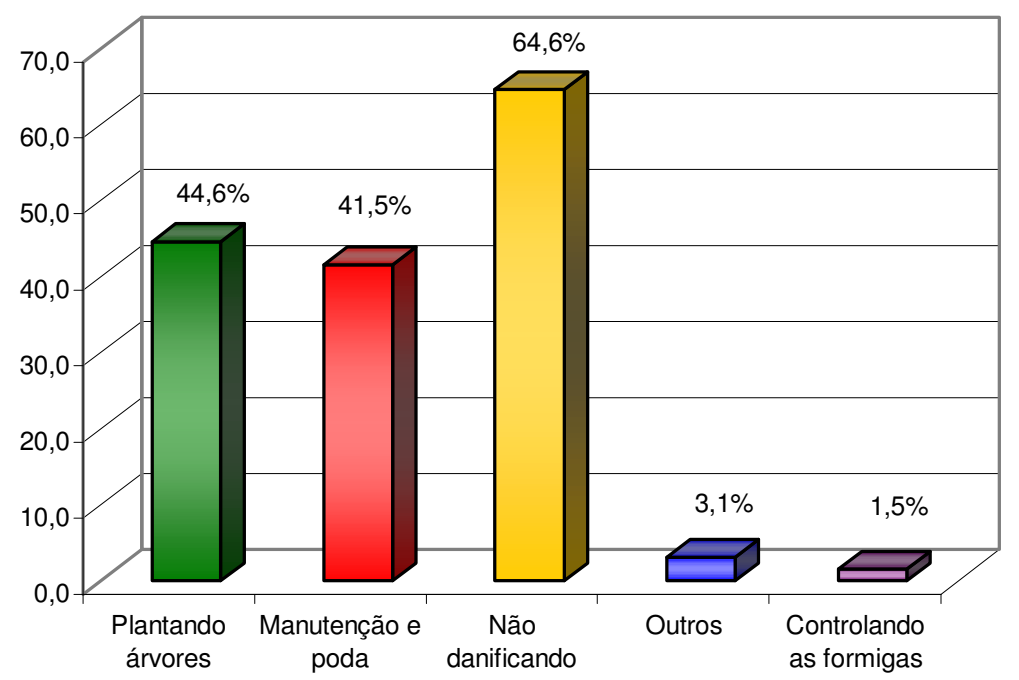

Figura 5: Formas de colaboração realizadas pelos moradores da Vila Estação Colônia, Bairro Camobi, Santa Maria, RS.

Com base na indicação de espécies preferidas para serem implantadas nas ruas, observou-se conforme a Figura 6, que $24,6 \%$ dos entrevistados indicaram que poderia ser implantada qualquer espécie arbórea nas ruas, não havendo preferência e nem preocupação com as espécies que fossem plantadas no bairro, o que indica a falta de conhecimento dos moradores quanto ao comportamento do desenvolvimento das espécies, resultando na tão conhecida relação conflituosa arborização e ambiente urbano, da qual as conseqüências todos nós deparamos diariamente; pois para Guzzo (2005) a escolha da espécie a ser plantada é o aspecto mais importante a ser considerado, sendo extremamente importante que seja considerado o espaço disponível que se tem, a presença ou ausência de fiação aérea e de outros equipamentos urbanos, largura da calçada e recuos, o que está vinculado ao conhecimento do porte da espécie a ser utilizada.

Embora, ter havido este grande percentual de desconhecimento por parte de alguns, outros $13,8 \%$ apontaram que deveriam ser implantadas espécies frutíferas, outros $13,8 \%$ desejariam espécies de sombra e $9,2 \%$ foi o total percentual obtido pelos que solicitaram a implantação de espécies de pequeno porte, médio porte e espécies adequadas, o que demonstra um bom grau de conhecimento deste último grupo quanto à questão de conflitos do elemento natural (árvores) com os elementos construídos dos centros urbanos, visto que demonstraram preocupação em relação ao porte das árvores. 

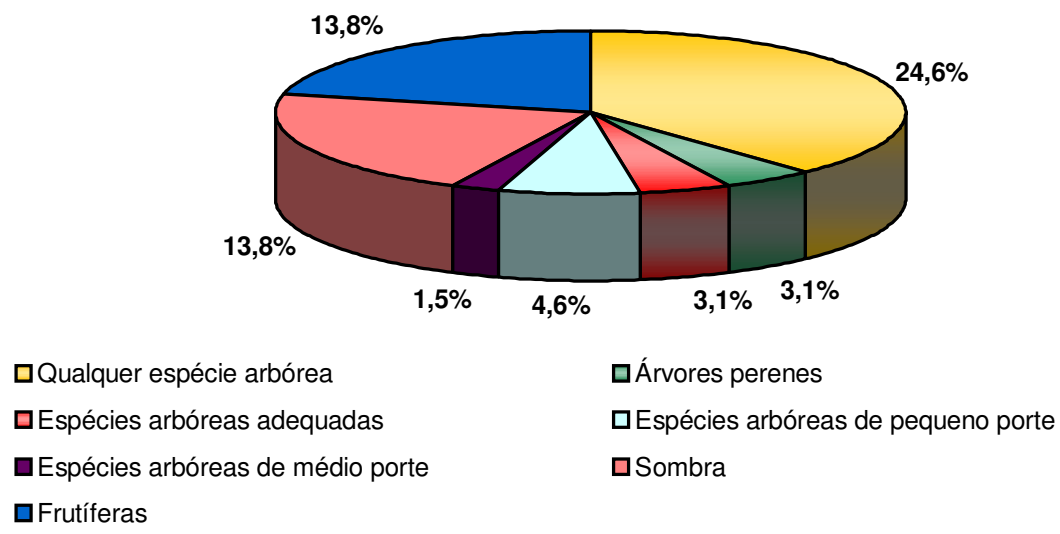

Figura 6: Espécies indicadas pelos entrevistados da Vila Estação Colônia, Bairro Camobi, Santa Maria, RS.

De acordo com a preferência dos moradores, as espécies mais citadas para serem implantadas na arborização da vila foram as seguintes: Melia azedarach L. (Cinamomo) com 10,8\%, Caesalpinia peltophoroides Benth. (Sibipiruna) e Inga sp. (Ingá) com 7,7\% e Ipê (Tabebuia sp.) com 4,6\%. Essas podem apresentar uma relação com as espécies presentes na arborização da vila, uma vez que possuímos a tendência de recordar em maior grau aquilo que vemos no dia-a-dia. Um levantamento realizado por Brun et al. (2005) permitiu conhecermos as 45 espécies existentes na Vila Estação Colônia, as quais perfazem um total de 237 indivíduos; sendo que o maior número de indivíduos encontrados foram os de Cinamomo totalizando 40 indivíduos, já para a Sibipiruna foram registrados 22 indivíduos, para os Ingás 15 indivíduos e 12 indivíduos de Ipês. Brun et al. (2005), ressalta ainda que a freqüência de ocorrência do Cinamomo (Melia azedarach) foi de 18,4\%, sendo que o recomendado é de que não se ultrapasse os $15 \%$, para que não ocorra a disseminação de doenças que podem levar a uma epidemia e morte dos exemplares, o que já foi verificado no Bairro, pois no ano de 2004 observou uma grande disseminação de doenças de ordem fotossintética ocasionadas por vírus na espécie, que tem atacado boa parte dos exemplares da composição ocasionando a morte da maioria dos exemplares atacados. Neste sentido se faz imprescindível um estudo sobre a escolha das espécies mais adequadas para o plantio em área urbana, pois a arborização concentrada em poucas espécies compromete o aspecto paisagístico e aumenta a possibilidade de ataque de pragas.

Entre outras espécies citadas com menor importância pelos moradores encontrase: Delonix regia (Boj.) Rafin. (Flamboyant), Citrus limon (L.) Burm. f.. (Limoeiro), Parapiptadenia rigida (Bentham) Brenan., (Angico-vermelho), Tipuana tipu (Benth.) Kuntze. (Tipuana), Ficus sp. (Figueiras), Cupressus sp. e Juniperus sp. (Ciprestes), Eugenia uniflora 
L. (Pitangueira), Caesalpinia ferrea Mart. (Pau-ferro), Syzygium cumini (L.) Skeels (Jambolão), Platanus acerifolia (Aiton) Willd. (Plátano) e Lagerstroemia indica L. (Extremosa).

$\mathrm{Na}$ opinião de $47,7 \%$ dos entrevistados, seria necessário implantar mais árvores para melhorar a arborização da sua vila, 44,6\% responderam ser fundamental efetuar a manutenção e as podas de formas e épocas adequadas, sendo que 53,8\% gostariam que fosse realizado um trabalho conscientização ecológica com a população quanto à importância da arborização urbana e formas de implantação e manutenção, o que deve ser encarado como uma forma de participação dos usuários finais da arborização, favorecendo assim para que o ser humano se volte mais para as questões ambientais e ao mesmo tempo perceba a importância da arborização urbana em sua vida. A falta de participação comunitária nos programas de arborização gera sérios prejuízos. Percebe-se nitidamente que o "vandalismo" tornou-se uma das mais conspícuas formas de interação entre o homem urbano e a arborização, por isso a educação da população com relação aos efeitos benéficos da arborização é uma forma de reduzir os seus efeitos deletérios (Malavasi \& Malavasi, 2001).

E por fim, os entrevistados foram consultados sobre a possibilidade de contribuir financeiramente para a manutenção da arborização urbana, destes 76,9\% afirmaram estar dispostos a contribuir e $23,1 \%$ responderam que não contribuiriam, sendo que os valores variaram de $R \$ 1,00$ a 50,00 anuais. Onde $16,9 \%$ da população afirmaram que contribuiria com até $R \$ 1,00$ anual, 24,6\% com $R \$ 1,00$ a 5,00 anual, $23,1 \%$ com $R \$ 5,00$ a 10,00 anual e o restante contribuiria com outras formas. Tendo como valor médio agregado $R \$$ 9,70 anuais para investimentos na arborização por morador que extrapolado para a população da Vila, 1.420 habitantes, resultaria em um investimento de $R \$ 13.774,00$ (ou US\$ 5988,70) por ano para ser aplicado na implantação de áreas não arborizadas, ou na manutenção da arborização já existente; porém, há um fato que desvia essa extrapolação do que realmente se espera, uma vez que nem todos habitantes contabilizados no cálculo possuem renda (crianças, donas de casa, etc.) e por isso acabariam não contribuindo.

Nota-se que os benefícios da arborização são muitas vezes de difícil valoração, o que pode tornar pequenas contribuições insignificantes diante de tal situação, mas que com o pouco de cada um adquire um valor razoável capaz de fazer muito pela arborização. Moll e Young (1992) levando em consideração o efeito de amenização da temperatura no verão e inverno assim como a redução na concentração de dióxido de carbono e partículas suspensas no ar estimaram que, em média, uma árvore na área urbana de uma cidade localizada em área de clima temperado fornece "benefícios" ambientais anuais no valor de US\$273,00 (duzentos e setenta e três dólares) (Malavasi \& Malavasi, 1994). Relacionando este valor com o valor médio agregado extrapolado pelo número de habitantes da Vila 
Estação Colônia, o total obtido cobriria apenas os "benefícios" ambientais fornecidos por 22 árvores, o que significa que do total das 217 árvores encontradas na vila, 195 destas não teriam seus "benefícios" ambientais pagos, aí encontramos um grande motivo para valorizarmos mais as nossas árvores urbanas, integrantes e formadoras de elos entre as diferentes estruturas do meio em que vivemos, nos proporcionam grandes benefícios sem pedir nada em troca, permanecem no espaço que lhes foi destinado mesmo que impróprio, mas raramente deixam de cumprir com o seu papel. As árvores fazem muito por nós, e nós o que fizemos por elas? Que valores Ihes damos?

\section{CONCLUSÕES}

Com base no presente estudo conclui-se que:

- Verificou-se que a população da Vila Estação Colônia tem bom nível de esclarecimento no que se refere à arborização urbana, uma vez que a maioria mostrou conhecimento a respeito de questões que abordavam a importância da arborização, seus benefícios e qualidade de vida.

- Entretanto, percebeu-se que para alguns entrevistados houve um certo grau de dificuldade nas questões do tipo aberta, evidenciado-se principalmente nos entrevistados com baixo grau de escolaridade.

- Percebe-se que não houve planejamento da arborização por parte dos órgãos competentes e verifica-se também uma ineficiência na manutenção da mesma.

- Atualmente a população vem sofrendo as conseqüências da falta de planejamento relacionado à arborização urbana, evidenciado, sobretudo pelo plantio de espécies inadequadas em locais impróprios como calçadas estreitas, próximas a postes de luz e em baixo da fiação elétrica.

- É de extrema urgência que a prefeitura dê início a um plano de arborização, especialmente para as áreas mais periféricas, carentes em arborização. Uma forma de se viabilizar esta questão seria realizar parcerias entre a universidade e a prefeitura.

- Para implantação de futuros projetos de arborização ou manutenção da arborização na Vila Estação Colônia, a Prefeitura Municipal poderá incluir em seu orçamento o total extrapolado sobre o valor do agregado médio $(R \$ 9,70)$ pela população ativa.

\section{REFERÊNCIAS BIBLIOGRÁFICAS}

PIVETTA, K. F. L.; SILVA FILHO, D. F. Arborização urbana.UNESP/ FCAV/ FUNEP: Jaboticabal, 2002. 69 p. (Boletim acadêmico). Disponível em: 
<http://Imq.esalq.usp.br/ dfsilva/lcf0300/arborizacao_urbana.pdf>. Acesso em 20 mai. 2005.

ZINKOSKI, A. E.; LOBODA, C. R. ARBORIZAÇÃO: UMA PERCEPÇÃO DO ESPAÇO URBANO NA ÁREA CENTRAL DE GUARAPUAVA, PR. In: VII Coloquio Internacional de Geocrítica. Anais... Santiago de Chile: Instituto de Geografía - Pontificia Universidade Católica de Chile, 2005. Disponível em: < http://www.ub.es/geocrit/7-colzinkoski.htm>. Acesso em: 20 set. 2005.

RIO, V.; OLIVEIRA, L. (org). Percepção Ambiental - A experiência brasileira. 2 ed. São Paulo: UFSCAR/Studio Nobel, 1999.

AMANTE, F. A. Carta de Enchente da Praça da Bandeira e Tijuca - RJ. Universidade Estadual do Rio de Janeiro / Instituto de Geografia. 110 p. Monografia (Graduação em Geografia). Rio de Janeiro, 2001.

FAGGIONATO, S. Percepção ambiental. Disponível em:

<http://educar.sc.usp.br/biologia/textos/m_a_txt4.html>. Acesso em: 20 set. 2005.

OKAMOTO, J. Percepção Ambiental e Comportamento. São Paulo: Plêiade, 1996. 200p.

MAROTI, P. S. Percepção Ambiental. Disponível em:

<http://www.lapa.ufscar.br/portugues/perc_amb.htm.>. Acesso em: 20 set. 2005.

MALAVASI, U. C.; MALAVASI, M. M. Avaliação da arborização urbana pelos residentes estudo de caso em Marechal Cândido Rondon, Paraná. Revista Ciência Florestal, v.11, n. 1, p. $189-193,2001$.

PREFEITURA MUNICIPAL DE SANTA MARIA. Mapa da cidade de Santa Maria, $22^{a}$ edição, 2002.

MORENO, J. A. Clima do Rio Grande do Sul. Porto Alegre: Secretaria da Agricultura, 1961. $73 \mathrm{p}$.

SPIAZZI, C. F. T. Análise dos aspectos populacionais, infra-estrutura e equipamentos urbanos das Vilas Soares do Canto, Jardim e Aparício de Moraes no Bairro Camobi - 
Santa Maria - RS. Monografia (Bacharelado em Geografia) - Universidade Federal de Santa Maria. 67 f. Santa Maria, 2002.

STRECK, E. V.; KÄMPF, N.; DALMOLIN, R. S. D.; KLAMT, E.; NASCIMENTO, P. C.; SCHNEIDER, P. Solos do Rio Grande do Sul. Editora da UFRGS, Porto Alegre. 2002. 107 p.

SANTOS, N. R. Z. dos; TEIXEIRA, I. F. Arborização de Vias Públicas: Ambiente X Vegetação. Santa Cruz do Sul: Instituição Souza Cruz, 2001. 135 p.

CASTRO, N. S. Arborização Urbana: poda, condução e legislação. São Paulo: SBAU, ano XII, $\mathrm{n}^{\circ}$ 01, 2004. 12 p. (Boletim informativo). Disponível em: <http://www.sbau.com.br/arquivos/1semestre2004.pdf>. Acesso em 12 set. 2005.

GUZZO, P. Arborização Urbana. Disponível em:

<http://educar.sc.usp.br/biologia/prociencias/arboriz.html>. Acesso em 18 set. 2005.

BRUN, F. G. k.; LONGHI, S. J.; BRUN, E. J.; MONTEIRO, J. S.; KLEINPAUL, J. J.; CECONI, D. E.; POLETTO, I.; MARTINS, F. B. ASPECTOS DOS EXEMPLARES ARBÓREOS DA ARBORIZAÇÃO URBANA DA VILA ESTAÇÃO COLÔNIA, BAIRRO CAMOBI - SANTA MARIA, RS. In: VI Simpósio Nacional e Congresso Latino-americano de Áreas Degradadas. Anais... Curitiba, PR, 2005. 


\section{ANEXO 1}

Questionário de avaliação da percepção sobre a arborização pelos moradores da vila Estação Colônia

Rua: Data:

\section{Entrevistado:}

1- Qual o número de moradores em sua residência?

\section{2- Grau de escolaridade do entrevistado:}

( ) analfabeto

( ) ensino fundamental incompleto

( ) ensino fundamental completo

( ) ensino médio incompleto

( ) ensino médio completo

( ) ensino superior incompleto

( ) ensino superior

\section{3- Como você classificaria a arborização de sua rua?}

( ) muito arborizada

( ) razoavelmente arborizada

( ) pouco arborizada

4- Quais as vantagens que você observa na arborização de sua rua?

( ) sombra

( ) redução de calor

( ) redução de poluição sonora

( ) redução de flores e frutos

( ) outras:

5- E quais as desvantagens que você observa na arborização de sua rua?

( ) sujeira das ruas e calçadas

( ) sujeira provocada pelos pássaros 
( ) redução da iluminação pública

( ) problemas com a rede elétrica ou telefônica

( ) problemas na calçada

( ) outras:

6- Caso seja necessário, a quem você encaminharia suas reclamações referentes à arborização urbana?

( ) prefeitura municipal

( ) companhias responsáveis pela telefonia e energia elétrica

( ) outros:

7- Você colabora com a arborização da sua vila, bairro? Se colabora, de que forma?

( ) colabora

( ) não colabora

( ) plantando árvores

( ) fazendo a manutenção e podando

( ) não danificando

( ) outras formas:

\section{8- Que espécies você gostaria que fossem plantadas em sua rua?}

9- Na sua opinião, o que deveria ser feito para melhorar a arborização de sua rua?

( ) implantar mais árvores

( ) fazer manutenção e realizar podas de forma e época corretas

( ) fazer um trabalho de conscientização ecológica sobre arborização

( ) outras formas: 
10- Caso fosse implantada a arborização em sua rua, com quanto você estaria disposto a contribuir para a manutenção da mesma?

( ) não realizaria contribuição

( ) até $R \$ 1,00$ anual

( ) de $R \$ 1,00$ a 5,00 anuais

( ) de $\mathrm{R} \$ 5,00$ a 10,00 anuais

( ) outras formas: 